IP Periodica Polytechnica

Mechanical Engineering

61(1), pp. 60-67, 2017

DOI: $10.3311 /$ PPme. 9682

Creative Commons Attribution (i)

RESEARCH ARTICLE

\section{Strain Energy Density Prediction of Mixed-Mode Crack Propagation in Functionally Graded Materials}

\author{
Nabil Benamara $^{1 *}$, Abdelkader Boulenouar ${ }^{1}$, Miloud Aminallah ${ }^{1}$
}

Received 30 June 2016; accepted after revision 17 November 2016

\begin{abstract}
The objective of this work is to present a numerical modeling of crack propagation path in functionally graded materials (FGMs) under mixed-mode loadings. The minimum strain energy density criterion (MSED) and the displacement extrapolation technique (DET) are investigated in the context of fracture and crack growth in FGMs. Using the Ansys Parametric Design Language (APDL), the direction angle is evaluated as a function of stress intensity factors (SIFs) at each increment of propagation and the variation continues of the material properties are incorporated by specifying the material parameters at the centroid of each finite element (FE). In this paper, several applications are investigated to check for the robustness of the numerical techniques. The defaults effect (inclusions and cavities) on the crack propagation path in FGMs are examined.
\end{abstract}

\section{Keywords}

Functionally graded materials, Strain energy density, Mixedmode, Displacement extrapolation, Stress intensity factor

\footnotetext{
${ }^{1}$ Department of Mechanical Engineering, Faculty of Technology, Laboratory of Materials and Reactive Systems, Djillali Liabes University of Sidi Bel-Abbes, BP. 89, City Larbi Ben Mhidi, 22000, Algeria

*Corresponding author, e-mail: benamara96@yahoo.fr
}

\section{Introduction}

Functionally Graded Materials (FGMs) are inhomogeneous materials which are widely used in technological application. In recent years, those materials have been especially studied its mechanical behaviors using different approaches. For the fracture of the FGMs, many studies have considered various crack problems in non-homogeneous materials: Using finite element method (FEM) analysis, Kim and Paulino [1] evaluated the mixed-mode fracture parameters in FGMs with three techniques: $\mathrm{Jk}^{*}$-integral method, the displacement correlation technique (DCT) and the modified crack-closure integral method (MCC). The same authors [2] used the interaction integral method (M-integral) for evaluation of mixed-mode SIFs in FGMs to simulate the crack growth in homogeneous and FGMs materials using the FEM. Rao and Rahman [3] used the element-free Galerkin method (EFG) for calculating SIFs in twodimensional FGMs of different arbitrary geometry of cracked plate. Marur and Tippur [4] studied the influence of material gradient and the crack position on the fracture parameters for edge-cracked FGM specimen. Tilbrook et al. [5] investigated the effects of gradient profile and crack geometry on crack-tip stresses and crack propagation path in FGMs. Chandran and Barsoum [6] used a generalized method to determine SIFs for cracks in FGMs, using the center cracked tension (CCT) specimen. Kim and Paulino [7] developed the FE methodology for fracture analysis in orthotropic FGMs where cracks are arbitrarily oriented. The displacement correlation technique (DCT) and the modified crack closure (MCC) are used to evaluate SIFs in orthotropic FGMs. Chang-chun et al. [8] used the coupled method to calculate the Rice's J-integral for dynamic fracture in single edge cracked FGM panel. Eshraghi and Soltani [9] investigated weight function approach to obtain SIFs for internal central circular crack in solid cylinder. Bahr et al. [10] used the same technique to analyze the crack growth behavior in FGMs and in particular materials with a rising crack growth resistance curve. Steigemann et al. [11] presented the numerical modeling of quasi-static crack growth in FGMs using the compact tension shear (CTS) specimen. Sladek et al. [12] proposed the meshless method based on the local Petrov-Galerkin 
approach for 2D crack problems in 2D anisotropic and FGMs. Kim and Paulino [13] investigated FEM with mesh refinement techniques and interaction integral method to simulate the mixed-mode crack growth in homogeneous and FGMs.

Under mixed-mode loadings, the crack propagation path is important for fracture behaviors analysis. In the literature, a number of fracture criteria have been developed by many researchers, such as the: the maximum circumferential stress (MCS) criterion proposed by Erdogan and Sih [14], the maximum energy release rate (MERR) criterion based on Griffith's theory [15], the minimum strain energy density (MSED) criterion introduced by $\mathrm{Sih}[16,17]$ and the crack-tip opening displacement (CTOD) criterion developed By Sutton et al. [18].

The objective of this study is to present a numerical modeling of crack propagation in FGMs. Using the APDL code [19], the displacement extrapolation method and the strain energy density theory are used to determine numerically the SIFs and the crack growth direction. The FE analysis is used to carry out this study. The defaults effect on the crack propagation path in FGMs is highlighted.

The present paper is organized as follows: Section 2 presents the numerical evaluation of SIFs and the crack growth direction. Section 3 explains methodology of crack extension modeling in FGMs. Section 4 provides some numerical applications. Finally, Section 5 presents some conclusions.

\section{Determination of fracture parameters \\ 2.1 Numerical evaluation of SIFs}

There are several techniques are used to obtain stress intensity factors (SIFs) in homogeneous and inhomogeneous materials, such as the displacement correlation technique (DCT) [20], the $\mathrm{J}_{\mathrm{k}}{ }_{\mathrm{k}}$-Integral $[21,22]$ and the modified crack-closure integral (MCC) [23]. The displacement extrapolation technique (DET) used to calculate the SIFs $\mathrm{K}_{\mathrm{I}}$ and $\mathrm{K}_{\mathrm{II}}$ for homogeneous materials [24-27] is modified to calculate the SIFs for non-homogeneous materials, in present study. For the FGMs, the SIFs $\mathrm{K}_{\mathrm{I}}$ and $\mathrm{K}_{\mathrm{II}}$ can be expressed as follows:

$$
\begin{gathered}
K_{I}=\frac{E_{t i p}}{3\left(1+v_{t i p}\right)\left(1+K_{t i p}\right)} \sqrt{\frac{2 \pi}{L_{e}}}\left[4\left(v_{b}-v_{d}\right)-\frac{\left(v_{c}-v_{e}\right)}{2}\right] \\
K_{I I}=\frac{E_{t i p}}{3\left(1+v_{t i p}\right)\left(1+K_{t i p}\right)} \sqrt{\frac{2 \pi}{L_{e}}}\left[4\left(u_{b}-u_{d}\right)-\frac{\left(u_{c}-u_{e}\right)}{2}\right]
\end{gathered}
$$

where:

$\mathrm{E}_{\text {tip }}$ is modulus of elasticity, $v_{\text {tip }}$ is Poisson's ratio, $\mathrm{K}_{\text {tip }}$ is elastic parameter equals to $3-4 v_{\text {tip }}$ or $\left(3-v_{\text {tip }}\right) /\left(1+v_{\text {tip }}\right)$ in the case of plane strain or plane stress, respectively.

$\mathrm{L}$ is element length. $\mathrm{u}$ and $\mathrm{v}$ are the displacement components in the $\mathrm{x}$ and $\mathrm{y}$ directions, respectively; the subscripts indicate their positions as shown in Fig. 1.
In this study, the special quarter point finite elements proposed by Barsoum are used [28] to obtain a better approximation of the field around the crack-tip (Fig. 1), where the midside node of the element connected to the crack-tip is moved to $1 / 4$ of the length of this element.

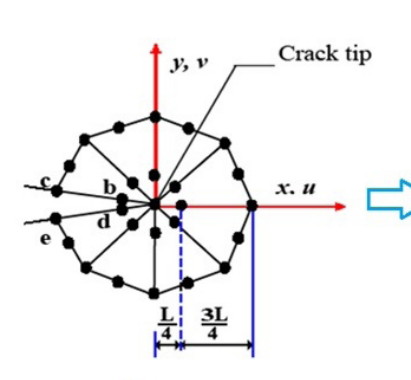

a)

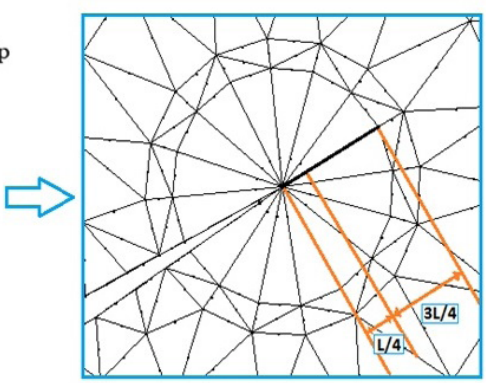

b)
Fig. 1 Singular element around the crack-tip: a) Barsoum elements, b) FE simulation.

\subsection{Crack increment direction}

Sih [17] used the strain as a critical parameter in order to propose the minimum strain energy density (MSED) criterion. It states that the direction of crack initiation coincides with the direction of minimum strain energy density along a constant radius around the crack tip. The MSED-criterion showed a good agreement with the experimental results obtained earlier by Erdogan and Sih [14]. In addition, this criterion is the only one that shows the dependence of the initiation angle on material property represented by Poisson's ratio $v$. In mathematical form, MSED-criterion can be stated as:

$$
\frac{\partial S}{\partial \theta}=0 \quad \text { and } \quad \frac{\partial^{2} S}{\partial \theta^{2}} \succ 0
$$

with

$$
S=\frac{d W}{d V} r
$$

where $\mathrm{dW} / \mathrm{dV}$ is the strain energy density function per unit volume, and $\mathrm{r}$ is a finite distance between the crack-tip and the point of failure initiation.

Under mixed mode conditions, the strain energy density factor $\mathrm{S}$ was given by $\mathrm{Sih}$ as follows:

$$
\begin{gathered}
S=\frac{1}{\pi r}\left(a_{11} K_{I}^{2}+2 a_{12} K_{I} K_{I I}+a_{22} K_{I I}^{2}\right) \\
a_{11}=\frac{1}{16 \mu_{t i p} \pi}\left[\left(K_{t i p}-\cos \theta\right)(1+\cos \theta)\right] \\
a_{22}=\frac{1}{16 \mu_{t i p} \pi}\left[\left(K_{t i p}+1\right)(1-\cos \theta)+(1+\cos \theta)(3 \cos \theta-1)\right] \\
a_{12}=\frac{1}{16 \mu_{t i p} \pi}\left[\sin \theta\left(2 \cos \theta-K_{t i p}+1\right)\right]
\end{gathered}
$$

where $v_{\text {tip }}$ is the shear modulus of elasticity. 
The unstable crack growth occurs when $\mathrm{S}_{\min }$ reaches a critical value, $\mathrm{S}_{\mathrm{cr}}$, i.e.,

$$
S_{\min }=S_{c r}=a_{11} K_{I}^{2}+2 a_{12} K_{I} K_{I I}+a_{22} K_{I I}^{2} \quad \text { for } \theta=\theta_{0} .
$$

where $\mathrm{S}_{\mathrm{cr}}$ is the critical value of strain energy density factor at the critical distance $r_{c}$.

The value $\mathrm{S}_{\text {cr }}$ is characteristic of the material and is related to $\mathrm{K}_{\mathrm{Ic}}$ by the relation in the case of Mode-I crack extension, i.e., $\mathrm{K}_{\mathrm{II}}=0$,

$$
S_{c r}=[(1-2 v) / 4 \pi \mu] K_{I c}^{2}
$$

\section{Finite element model}

In this paper, the APDL code has been employed for creating the program to simulate the mixed-mode crack propagation in FGMs. The displacement extrapolation technique and the minimum strain energy density theory are used, to determine the SIFs and the crack direction. The crack propagation in FGMs is characterized by successive propagation steps performed without user interaction. For this modeling, each step (at each increment of propagation $\Delta$ a) consists of:

1. Importing the initial geometry with the initial crack

2. Input material properties data of the problem.

3. Discretization of the FE model by plane2 elements 'PLANE183'.

4. Mesh definition.

5. FE analysis.

6. FE evaluation of SIFs $\mathrm{K}_{\mathrm{I}}$ and $\mathrm{K}_{\mathrm{II}}$.

7. Prediction of crack growth direction $\theta$.

8. Continues analysis (SIF $\mathrm{K}_{\mathrm{I}}>0$ )? If no, go to step 9. If yes, go to step 10 .

9. Stop.

10. Automatic delete of the crack segment and insertion of the new crack-tip position.

\section{Return to Step 4.}

Figure 2 shows the algorithm of the main operations for the crack propagation modeling using SED theory.

\section{Numerical results and discussion \\ 4.1 FE evaluation of SIFs}

For this problem, the geometry of the single edge cracked FGM plate with an initial crack of length a is considered for 2-Dimensional FE analysis (Fig. 3a). This geometry was originally investigated by Erdogan and $\mathrm{Wu}$ [29], and it is one of the few analytical solutions available for fracture in FGMs.

The plate is subjected to uni-axial loading at the both ends. The elastic modulus for FGMs plate was assumed to follow an exponential function given by:

$$
E(x)=E_{1} \exp (\lambda x) ; \quad 0 \leq x \leq w ;
$$

with $\mathrm{E}=\mathrm{E}_{1}(0), \mathrm{E}=\mathrm{E}_{2}(\mathrm{w})$, and $\lambda=\ln \left(E_{2} / E_{1}\right)$.
The following data were used under plane strain conditions: $\sigma=1$ unite, $\mathrm{E}_{1}=1$ unite; $\mathrm{E}_{2} / \mathrm{E}_{1}=(0.1,0.2,1,5$ and 10$) ; v=0.3$; $\mathrm{a} / \mathrm{w}=0.2,0.3,0.5$ and $0.6 ; \mathrm{L} / \mathrm{w}=8$.

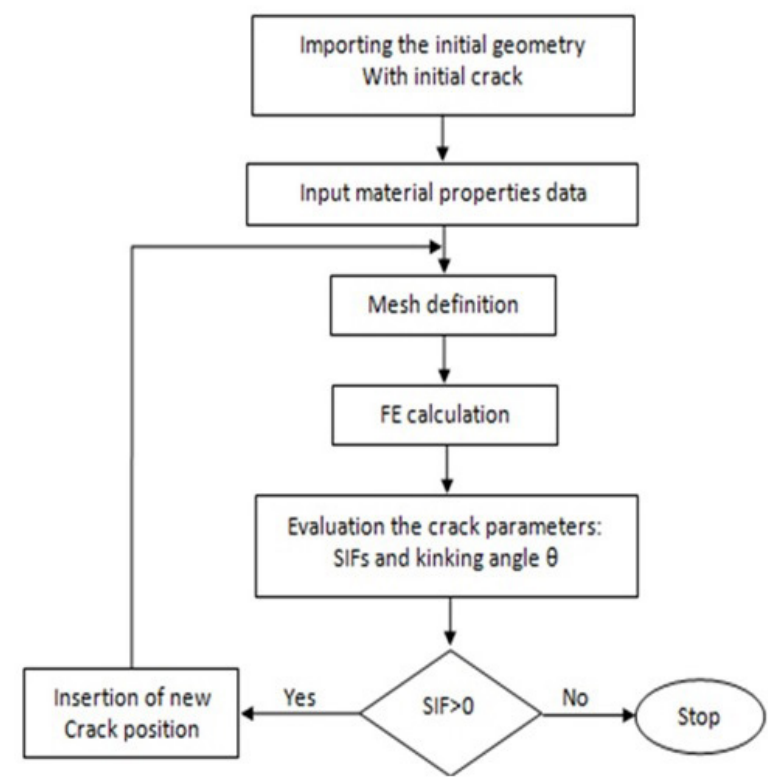

Fig. 2 A flowchart of the crack propagation simulation in FGMs

The FE standard code ANSYS [19] has been used for modeling the problem. The special quarter point finite elements proposed by Barsoum are used [28] for modeling the singular field around the crack-tip (see Fig. 1b). For a/w=0.2, the mesh discretization consists of 710 elements and 2241 nodes (Fig. 3b).

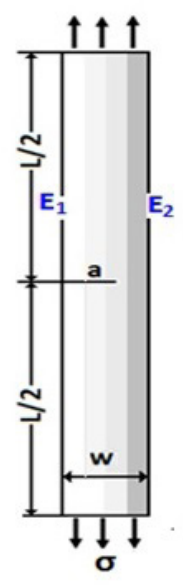

a)

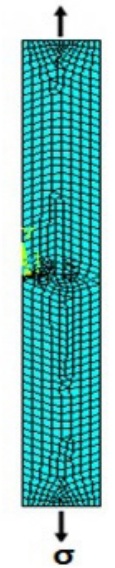

b)
Fig. 3 (a) Geometry and boundary conditions of FGM plate $(\mathrm{a} / \mathrm{w}=0.2)$

Figure 4 shows the variation of normalized SIFs obtained by the displacement extrapolation technique (DET) are compared with the numerical results obtained by Chen et al. [30] using the element free Galerkin (EFG) method and by Kim and Paulino [31] using $\mathrm{J}_{\mathrm{k}}{ }^{*}$-Integral method and the displacement correlation technique (DCT), respectively. The results obtained indicate good agreement between ours results and other author's 

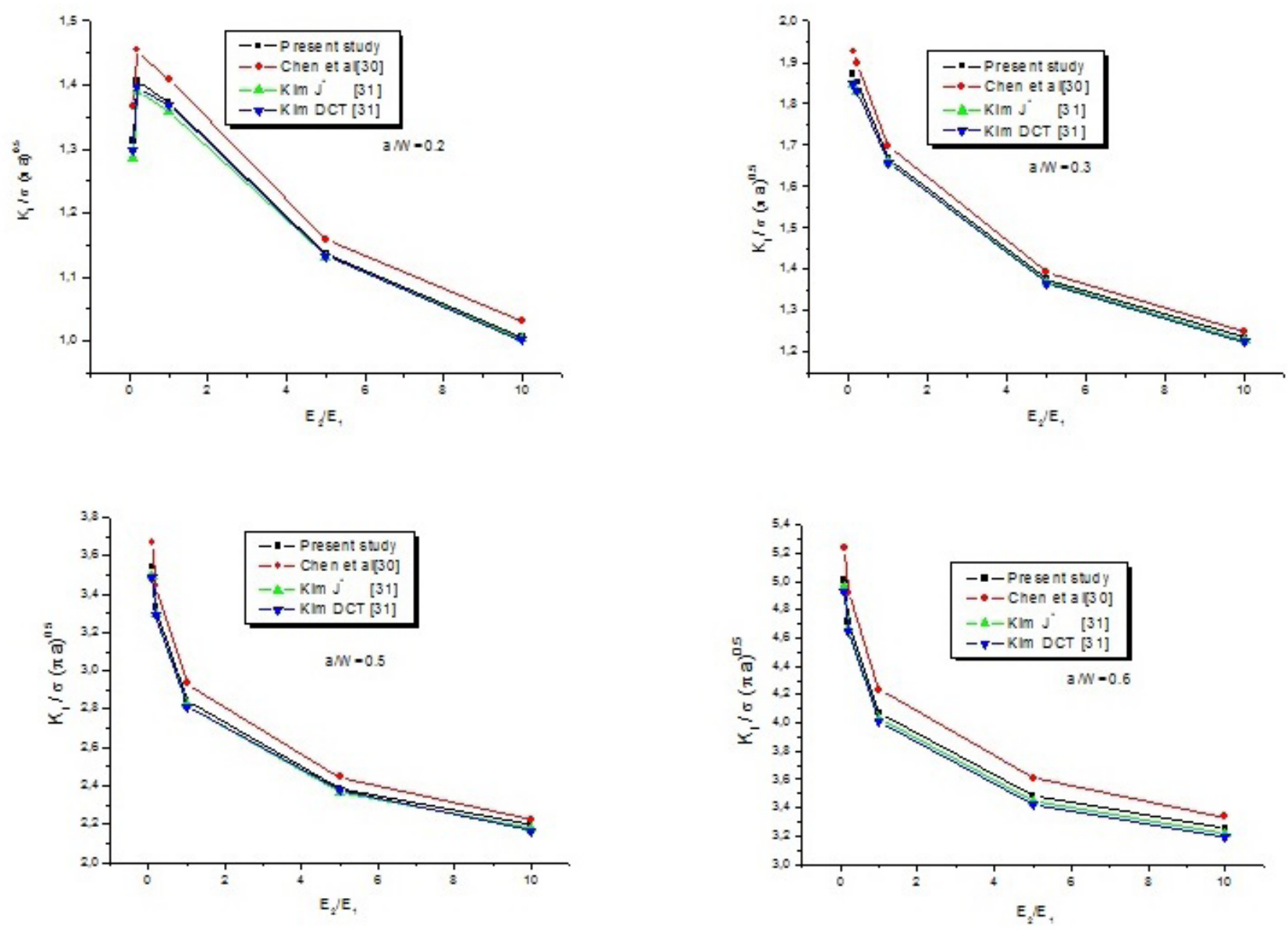

Fig. 4 Normalized SIFs for edge cracked FGM plate for : $\mathrm{a} / \mathrm{w}=0.2,0.3,0.5$ and 0.6

solution $[32,33]$. These results allow us to conclude that the numerical model implemented in FE code, correctly described the stress-strain field around the crack-tip and the behavior of elastic FGM.

\subsection{Crack propagation simulation in FGM}

In order to show the robustness of our strategy of crack propagation simulation, four examples are presented (single edge cracked plate, FGM plate with an oblique pre-crack, single edge cracked plate with one hole and another with an inclusion). The variation of the elastic modulus for FGM is modeled by Eq. (8).

\subsubsection{Single edge cracked FGM plate}

In present problem, we consider the single edge cracked FGM plate with $\mathrm{L} / \mathrm{w}=2$ and $\mathrm{a} / \mathrm{w}=0.5$. The plate is imposed by a plane stress condition under uni-axial loading (Fig. 5a). A typical integration grid of the cracked plate is illustrated in Fig. 5b. For first step of crack propagation, the number of element used in this analysis is 1043 elements with 3196 nodes.

Figure 6 illustrates three steps for extension of initial crack in FGM plate. As expected, the crack propagates horizontally, depending on mode-I loading. During crack propagation, the crack path is regular and the concentric mesh keeps good accuracy at the crack-tip. The results obtained allow us to conclude that the SED criterion incorporated in FE code gives a good crack growth under opening mode. Figure 7 shows the positions of the crack-tip during the crack extension obtained for homogeneous and FGM obtained for homogeneous (with $\mathrm{E}_{2} / \mathrm{E}_{1}=1$ ) and FGM plates. The results obtained show a good correlation between the trajectories estimated for the two plates using the SED theory.

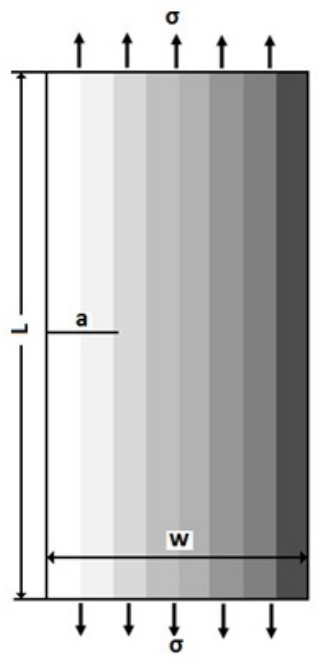

a)

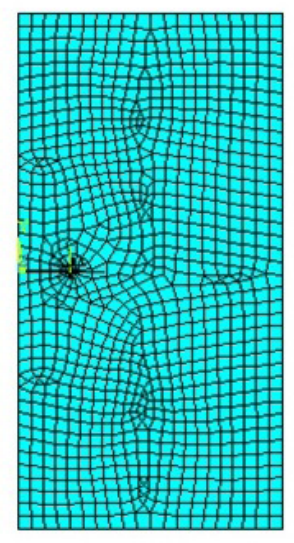

b)
Fig. 5 a) Geometrical model of the cracked FGM plate and b) final mesh for initial configuration 

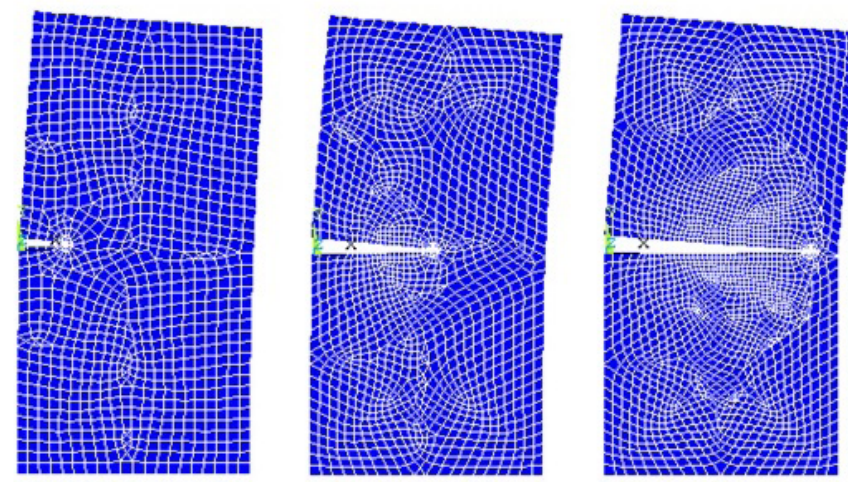

Fig.6 Three steps of crack propagation trajectory for single edge cracked FGM plate

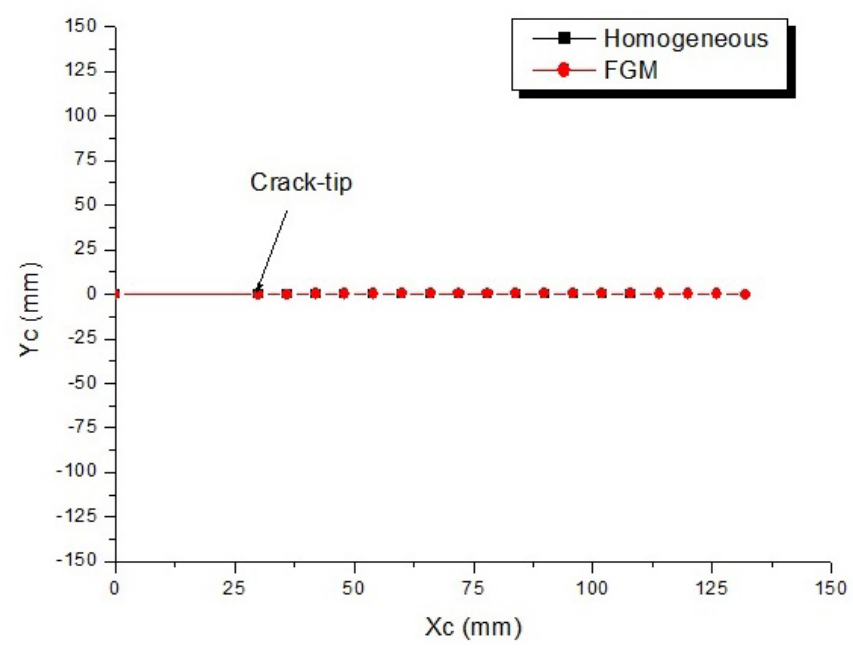

Fig. 7 Crack trajectories obtained for homogeneous and FGM.

\subsubsection{FGM plate with an oblique pre-crack}

In the present problem, we consider a thin rectangular FGM plate with an oblique pre-crack (with $\alpha=30^{\circ}$ ). This plate is submitted under uni-axial loading. A rectangular isotropic FGM plate with an oblique crack and final mesh for the first configuration of crack propagation are illustrated in Fig. 8. The numerical modeling is performed under plane stress conditions.
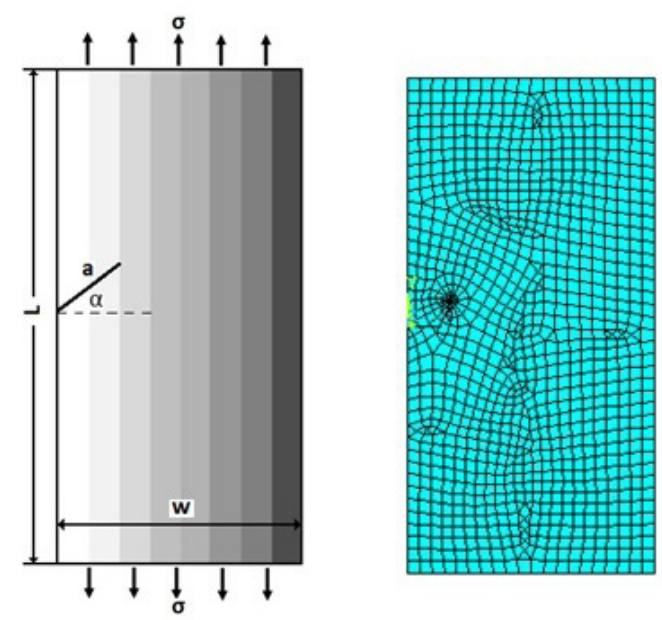

Fig. 8 Geometry model and final mesh for initial configuration
Figure 9 shows three steps for crack propagation path obtained for inclined crack in FGM plate. Figure 10 illustrates the positions of the crack-tip during the crack extension obtained for homogeneous and FGM plates. For two materials, the crack propagated and reoriented horizontally under mode I loading.
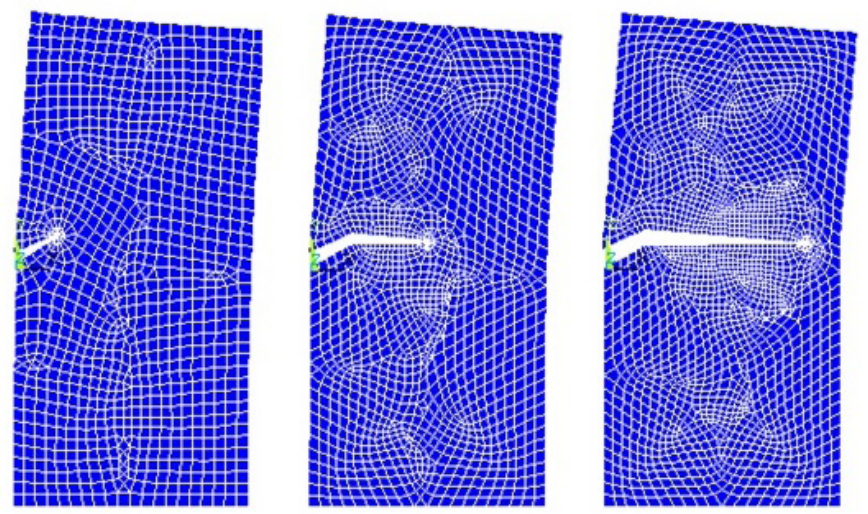

Fig. 9 Crack propagation path of the inclined crack

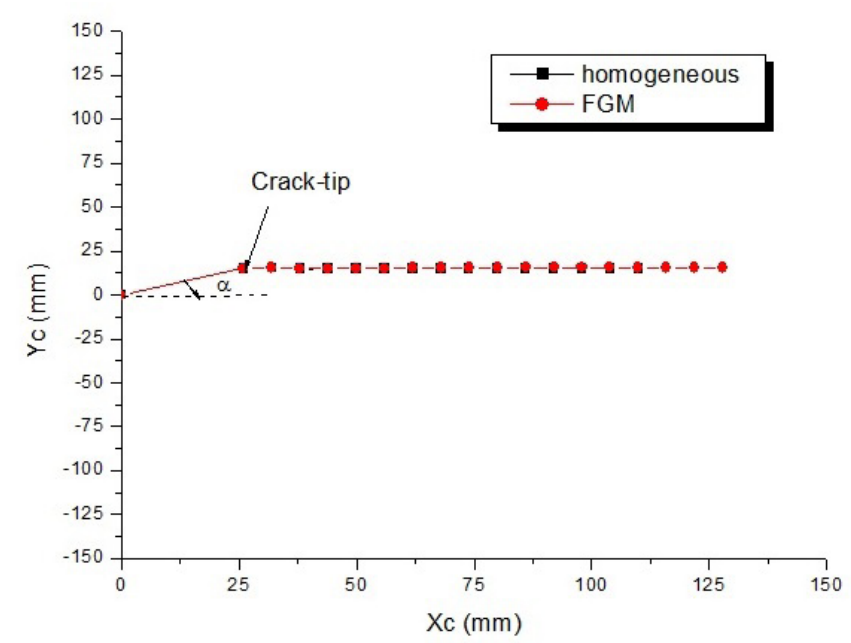

Fig. 10 Positions of the crack-tip during the crack extension obtained for homogeneous and FGM

\subsubsection{Single edge cracked FGM plate with one hole}

In order to determine the effect of a geometrical defect on the crack extension in FGMs, we represented in Fig. 11a the geometry of the single edge cracked plate with one hole. This plate is simply fixed at the bottom edge and loaded by uni-axial traction along the top edge. The geometry is meshed using 8-node quadratic elements and triangular elements concentric at crack-tip (Fig. 11b). The determination of SIFs, direction angle and crack growth path are made under plane stress problem.

Under plane stress conditions, the numerical calculations obtained for crack growth path will compare with other results, for a homogeneous material case. Figure 12 shows the final configuration corresponding to the last position of crack-tip for the results predicted in Refs [34] and [35], and that obtained in present study. The crack propagation paths obtained are similar between them [32]. 


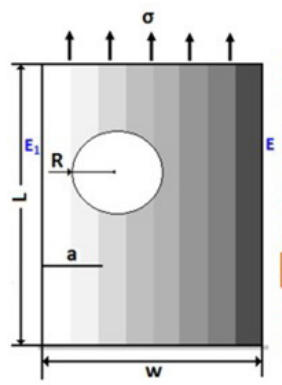

(a)

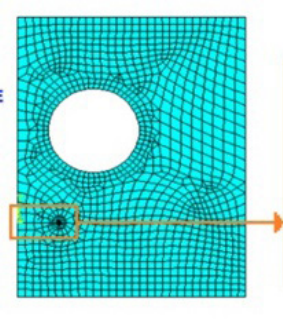

(b)

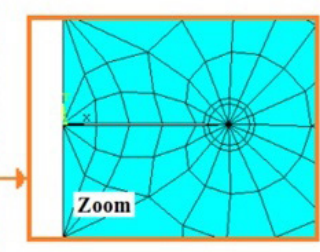

(c)
Fig. 11 a) Geometry model of cracked FGMs plate with one hole, b) typical FE mesh for initial configuration and c) singular element around the crack-tip

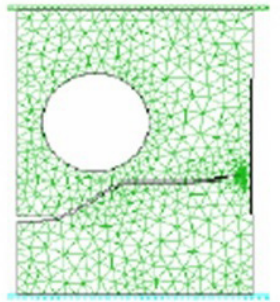

a)

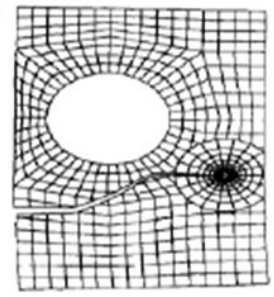

b)

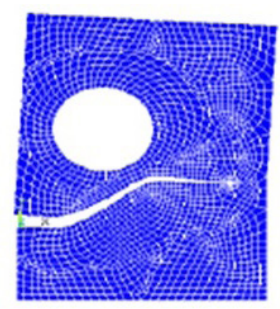

c)
Fig. 12 Final configuration corresponding to the last position of crack-tip (with $\mathrm{E}_{2} / \mathrm{E}_{1}=1$ ): a) Bouchard et al. [33], b) Rashid [34] and c) Present study

Figure 13 shows four positions for crack extension in FGM plate. This crack would move in a straight path if there was no hole at the plate for opening-mode (mode-I) loading (Fig. 13a). However, due to the presence of the default, the crack did not follow a straight line path, but curved towards the hole as shown in Fig. 13b. This was due to the stress concentration effect; cracks are likely to initiate at a hole boundary. Once the cracktip has moved beyond the default, the crack reoriented horizontally in the mode I loading as shown in Figs. 13c and 13d.

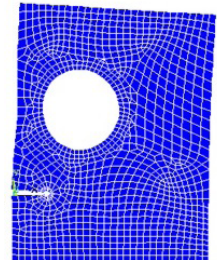

a)

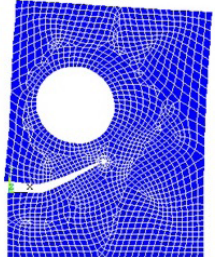

b)

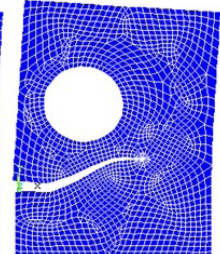

c)

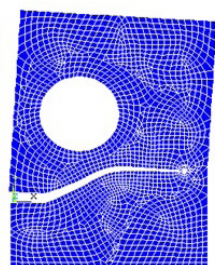

d)
Fig. 13 Four steps of crack propagation trajectory for a single edge cracked FGM plate with one hole

Figure 14 illustrates the crack trajectories obtained for homogeneous and FGMs plates, respectively. One can notice the same crack propagation behavior for both plates but the two crack paths are different from each other. This may explain the fact that the stress distribution around the hole is different for the two plates, which may directly influence on the crack propagation trajectory.

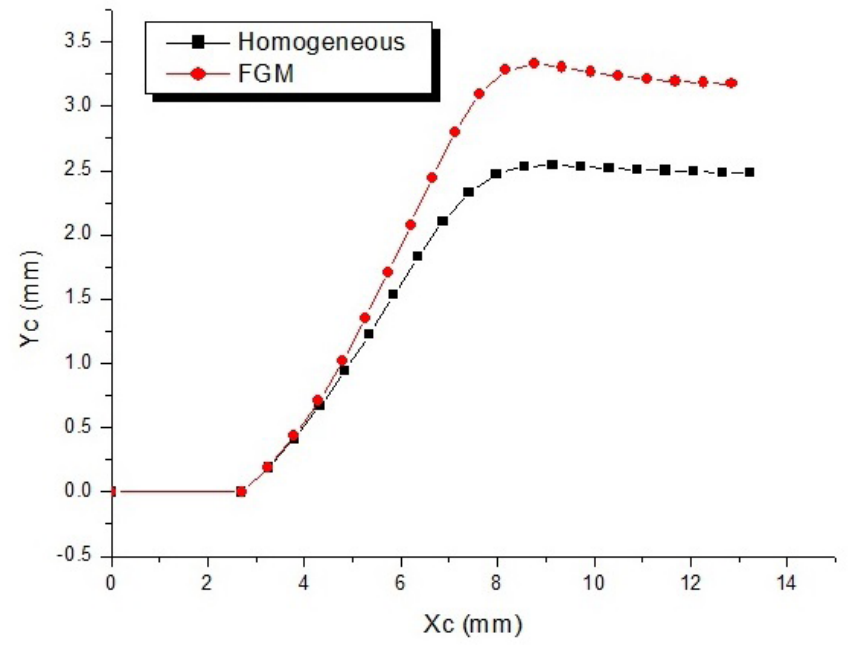

Fig. 14 Positions of the crack-tip obtained for homogeneous and FGM

\subsubsection{Cracked FGM plate with an inclusion}

In the last application, we studied the inclusion effect on the crack path in functionally graded materials. For this purpose, we considered a pre-cracked FGM plate with a circular inclusion, having the following dimensions: $\mathrm{W} / \mathrm{R}=3.5$ and $\mathrm{L} / \mathrm{W}=0.5$ (Fig. 15a) $[32,33]$. The FGM plate is fixed at the bottom edge and loaded by uni-axial traction along the top edge. A typical FE model of the FGM plate with an inclusion is shown in Fig. 15b. The determination of SIFs, direction angle and crack growth path are made under plane stress problem.

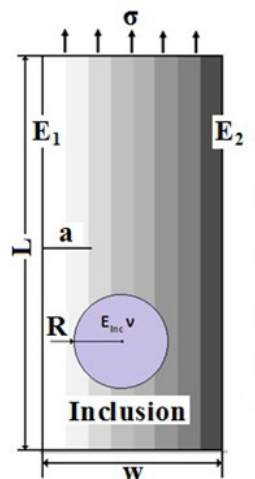

a)

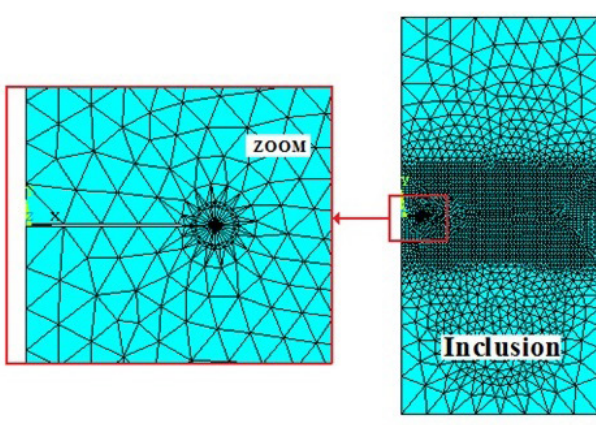

b)
Fig. 15 a) Geometrical model of the cracked FGM plate with an inclusion and b) typical FE mesh

The inclusion considered is characterized by its Poisson's ratio $v_{\text {Inc }}=v=0.3$ and Young's modulus $\mathrm{E}_{\text {Inc }}$. The mechanical properties of the FGM plate are given in Section 4.1.

Firstly, our numerical model was to check for a homogeneous material and the results obtained are compared with the numerical results obtained by Bouchard et al. [36]. The crack propagation trajectories are obtained for two cases $[32,33]$ :

a) $\mathrm{E}_{\text {Inc }} / \mathrm{E}_{1}=0.1$ and $\mathrm{E}_{2} / \mathrm{E}_{1}=1$ (Fig. 16a),

b) $\mathrm{E}_{\mathrm{Inc}} / \mathrm{E}_{1}=10$ and $\mathrm{E}_{2} / \mathrm{E}_{1}=1$ (Fig. 16b). 
The predicted crack propagation trajectory of the present study is quite similar to that obtained by Bouchard et al. [36].

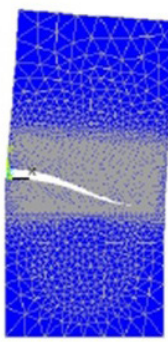

Present study

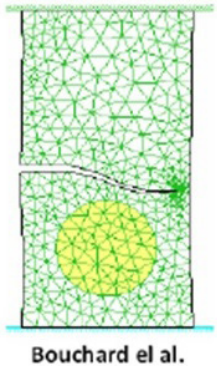

a)

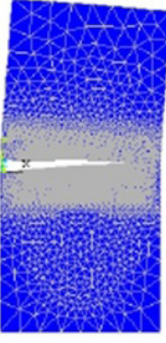

Present study

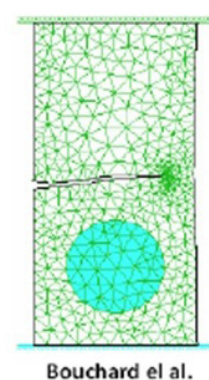

b)

Fig. 16 Final configuration corresponding to the last position crack-tip:

$$
\text { a) } \mathrm{E}_{\mathrm{Inc}} / \mathrm{E}_{1}=0.1 \text {, b) } \mathrm{E}_{\mathrm{Inc}} / \mathrm{E}_{1}=10
$$

For FGM plate case, the prediction of the crack propagation path, for two cases $\mathrm{E}_{\text {Inc }}<\mathrm{E}_{1}$ (with $\mathrm{E}_{\text {Inc }} / \mathrm{E}_{1}=0.1$ ) and $\mathrm{E}_{\text {Inc }}>\mathrm{E}_{2}$ (with $\mathrm{E}_{\mathrm{Inc}} / \mathrm{E}_{2}=10$ ) is shown in Fig. 17. The obtained results show that:

- If $\mathrm{E}_{\text {Inc }} / \mathrm{E}_{1}=0.1$, the inclusion is less rigid than the FGM, the crack is attracted to the inclusion (Fig. 17a).

- If $\mathrm{E}_{\mathrm{Inc}} / \mathrm{E}_{1}=10$, the inclusion is more rigid than the FGM, the crack is moving away from the inclusion (Fig. 17b).

Figure 18 illustrates the crack trajectories obtained in FGM plate for the two cases.
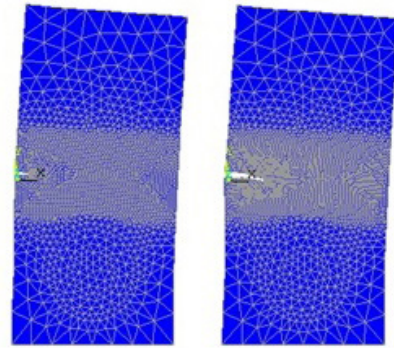

a)
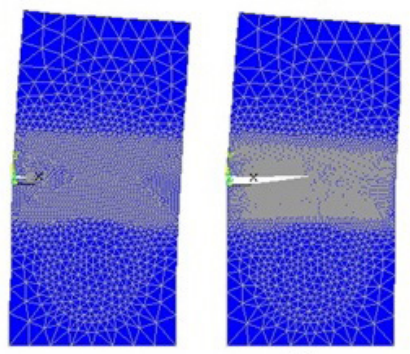

b)

Fig. 17 Crack propagation trajectory obtained for FGM plate with an inclusion: a) $\left.\mathrm{E}_{\mathrm{Inc}} / \mathrm{E}_{1}=0.1, \mathrm{~b}\right) \mathrm{E}_{\mathrm{Inc}} / \mathrm{E}_{2}=10$.

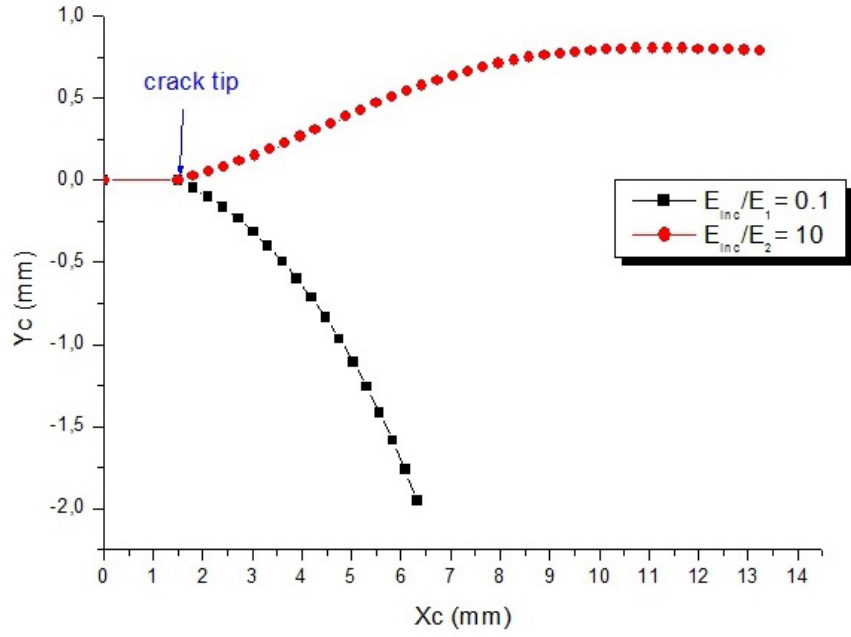

Fig. 18 Positions of the crack-tip obtained for FGM plate with an inclusion

\section{Conclusion}

This work investigates mixed-mode crack growth in FGMs plates using the Ansys Parametric Design Language. Under mode-I loading, the SIFs for a single edge cracked plate was evaluated and compared with available analytical and numerical solutions. The comparison shows that our numerical technique is capable of demonstrating the SIF evaluation and the crack path direction satisfactorily. The methodology of crack propagation modeling proposed in this investigation has been used successfully to predict the crack path for homogeneous $\left(\mathrm{E}_{2} / \mathrm{E}_{1}=1\right)$ and $\mathrm{FGM}$ plates $\left(\mathrm{E}_{2} / \mathrm{E}_{1} \neq 1\right)$.

The presence of holes and inclusions in the plates disturbed the stress and strain fields providing interesting crack trajectories. The results indicated that FE analysis for fracture mechanics problems has been successfully employed for homogenous and FGM. Based on the results, it was recommended to add further development the APDL code to simulate crack propagation in orthotropic FGMs.

\section{References}

[1] Kim, J. H., Paulino, G. H. "Finite element evaluation of mixed mode stress intensity factors in functionally graded materials." International Journal for Numerical Methods in Engineering. 53, pp. 1903-1935. 2002. https://doi.org/10.1002/nme.364

[2] Kim, J. H., Paulino, G. H. "Simulation of crack propagation in functionally graded materials under mixed-mode and non-proportional loading." International Journal of Mechanics and Materials in Design. 1, pp. 63-94. 2004. https://doi.org/10.1023/B:MAMD.0000035457.78797.c5

[3] Rao, B. N., Rahman, S. "Mesh-free analysis of cracks in isotropic functionally graded materials." Engineering Fracture Mechanics. 70(1), pp. 1-27. 2003. https://doi.org/10.1016/s0013-7944(02)00038-3

[4] Marur, P. R., Tippur, H. V. "Numerical analysis of crack-tip fields in functionally graded materials with a crack normal to the elastic gradient." International Journal of Solids and Structures. 37, pp. 5353-5370. 2000. https://doi.org/10.1016/S0020-7683(99)00207-3

[5] Tilbrook, M. T., Moon, R. J., Hoffman, M. "Finite element simulations of crack propagation in functionally graded materials under flexural loading." Engineering Fracture Mechanics. 72, pp. 2444-2467. 2005.

https://doi.org/10.1016/j.engfracmech.2005.04.001 
[6] Chandran, K. S. R., Barsoum, I. "Determination of stress intensity factor solutions for cracks in finite-width functionally graded materials." International Journal of Fracture. 121, pp. 183-203. 2003. https://doi.org/10.1023/B:FRAC.0000005346.83147.b2

[7] Kim, J. H., Paulino, G. H. "Mixed-mode fracture of orthotropic functionally graded materials using finite elements and the modified crack closure method." Engineering Fracture Mechanics. 69, pp. 1557-1586. 2002. https://doi.org/10.1016/S0013-7944(02)00057-7

[8] Hun, W. C., Peixiang, H., Ziran, L. "Extension of J integral to dynamic fracture of functional graded material and numerical analysis." Computers and Structures. 80, pp. 411-416. 2002. https://doi.org/10.1016/S0045-7949(02)00013-5

[9] Eshraghi, I., Soltani, N. "Stress intensity factor calculation for internal circumferential cracks in functionally graded cylinders using the weight function approach." Engineering Fracture Mechanics. 134, pp. 1-19. 2015. https://doi.org/10.1016/j.engfracmech.2014.12.007

[10] Bahr, H. A., Balke, H., Fett, T., Hofinger, I., Kirchhoff, G., Munz, D., Neubrand, A., Semenov, A. S., Weiss, H. J., Yang, Y. Y. "Cracks in functionally graded materials." Materials Science and Engineering. A362, pp. 2-16. 2003. https://doi.org/10.1016/S0921-5093(03)00582-3

[11] Steigemann, M., Neugebauer, M. S., Fulland, M., Richard, H. A. "Simulation of crack paths in functionally graded materials." Engineering Fracture Mechanics. 77, pp. 2145-2157. 2010. https://doi.org/10.1016/j.engfracmech.2010.03.022

[12] Vladimir, J. S., Chuanzeng, S., Tan, Z. C. L. "Evaluation of fracture parameters for crack problems in FGM by a meshless method." Journal of Theoretical and Applied Mechanics. 44(3), pp. 603-636. 2006.

[13] Kim, J. H., Paulino, G. H. "On Fracture Criteria for Mixed-Mode Crack Propagation in Functionally Graded Materials." Mechanics of Advanced Materials and Structures. 14, pp. 227-244. 2007. https://doi.org/10.1080/15376490600790221

[14] Erdogan, F., Sih, G. C. "On the crack extension in plane loading and transverse shear." Journal of Basic Engineering. 85, pp. 519-527. 1963. https://doi.org/10.1115/1.3656897

[15] Griffith, A. A. "The phenomena of rupture and flow in solids." Philosophical Transactions of the Royal Society A. 221, pp. 163-198. 1921. https://doi.org/10.1098/rsta.1921.0006

[16] Sih, G. C. "A special theory of crack propagation: methods of analysis and solutions of crack problems." In: Mechanics of Fracture I. (Sih, G. C. (ed.)), Noordhoff International Publishing, Leyden, pp. 21-45. 1973.

[17] Sih, G. C. "Strain energy-density factor applied to mixed mode crack problem." International Journal of Fracture. 10(3), pp. 305-321. 1974. https://doi.org/10.1007/BF00035493

[18] Sutton, M. A., Deng, X., Ma, F., Newman, Jr. J. C., James, M. "Development and application of a crack tip opening displacement- Based mixed mode fracture criterion." International Journal of Solids and Structures. 37, pp. 3591-3618. 2000. https://doi.org/10.1016/S0020-7683(99)00055-4

[19] ANSYS, Inc. "Programmer's Manual for Mechnical APDL." Release 12.1, 2009.

[20] Shih, C. F., deLorenzi, H. G., German, M. D. "Crack extension modeling with singular quadratic isoparametric elements." International Journal of Fracture. 12, pp. 647-651. 1976. https://doi.org/10.1007/BF00034654

[21] Eischen, J. W. "An improved method for computing the J2 integral." Engineering Fracture Mechanics. 26, pp. 691-700. 1987. https://doi.org/10.1016/0013-7944(87)90134-2
[22] Eischen, J. W. "Fracture of non-homogeneous materials." International Journal of Fracture. 34, pp. 3-22. 1987. https://doi.org/10.1007/BF00042121

[23] Rybicki, E. F., Kanninen, M. E. "A finite element calculation of stress intensity factors by a modified crack closure integral." Engineering Fracture Mechanics. 9, pp. 931-938. 1977. https://doi.org/10.1007/BF00370563

[24] Boulenouar, A., Benouis, A., Benseddiq, N. "Numerical modelling of crack propagation in cement PMMA: Comparison of different criteria." Materials Research. 19(4), pp. 846-855. 2016 https://doi.org/10.1590/1980-5373-MR-2015-0784

[25] Boulenouar, A., Benseddiq, N., Mazari, M. "Strain energy density prediction of crack propagation for 2D linear elastic materials." Theoretical and Applied Fracture Mechanics. 67-68, pp. 29-37. 2013.

https://doi.org/10.1016/j.tafmec.2013.11.001

[26] Boulenouar, A., Benseddiq, N., Mazari, M. "Two-dimensional numerical estimation of stress intensity factors and crack propagation in linear elastic analysis." Engineering, Technology \& Applied Science Research. 5, pp. 506-510. 2013. URL: etasr.com/index.php/etasr/article/view/363/213

[27] Boulenouar, A., Benseddiq, N., Mazari, M., Benamara, N. "FE model for linear-elastic mixed mode loading: Estimation of sifs and crack propagation." Journal of Theoretical and Applied Mechanics. 52(2), pp. 373383. 2014. URL: www.ptmts.org.pl/2014-2-boulenouar-in.pdf

[28] Barsoum, R. S. "On the use of isoparametric finite element in linear fracture mechanics." International Journal for Numerical Methods in Engineering. 10, pp. 25-37. 1974. https://doi.org/10.1002/nme.1620100103

[29] Erdogan, F., Wu, B. H. "The surface crack problem for a plate with functionally graded properties." ASME Journal of Applied Mechanics. 54, pp. 449-456. 1997. https://doi.org/10.1115/1.2788914

[30] Chen, J., Wu, L., Du, S. "A modified J-integral for functionally graded materials." Mechanics Research Communications. 27, pp. 301-306. 2000. https://doi.org/10.1016/S0093-6413(00)00096-3

[31] Kim, J. H., Paulino, G. H. "Finite element evaluation of mixed mode stress intensity factors in functionally graded materials." International Journal for Numerical Methods in Engineering. 53, pp. 1903-1935. 2002. https://doi.org/10.1002/nme.364

[32] Boulenouar, A., Benamara, N., Merzoug, M. "Prediction of MixedMode Crack Propagation Paths in FGMs." In: 2nd CIMDD, University M'hamed Bougara Boumerdes, Algeria, 2015.

[33] Benamara, N., Boulenouar, A., Aminallah, M. "Strain energy density prediction of mixed-mode crack propagation in functionally graded materials." In: FRAT3, Hassiba Benbouali, University of Chlef, Algeria, 2016

[34] Bouchard, P. O., Bay, F., Chastel, Y., Tovena, I. "Crack propagation modelling using an advanced remeshing." Computer Methods in Applied Mechanics and Engineering. 189, pp. 723-742. 2000. https://doi.org/10.1016/S0045-7825(99)00324-2

[35] Rashid, M. M. "The arbitrary local mesh replacement method: An alternative to remeshing for crack propagation analysis." Computer Methods in Applied Mechanics and Engineering. 154, pp. 133-150. 1988. https://doi.org/10.1016/S0045-7825(97)00068-6

[36] Bouchard, P. O., Bay, F., Chastel, Y. "Numerical modelling of crack propagation: automatic remeshing and comparison of different criteria." Computer Methods in Applied Mechanics and Engineering. 192, pp. 3887-3908. 2003. https://doi.org/10.1016/S0045-7825(03)00391-8 